\title{
Detection of internal and external faults of single-phase induction motor using current signature
}

\author{
Marwan Abdulkhaleq Al-Yoonus, Omar Sharaf Al-deen Alyozbaky \\ Electrical Department, College of Engineering, University of Mosul, Ninava, Iraq
}

\begin{tabular}{l}
\hline \hline Article Info \\
\hline Article history: \\
Received Jul 16, 2020 \\
Revised Sep 9, 2020 \\
Accepted Dec 5, 2020 \\
\hline
\end{tabular}

\section{Keywords:}

Current signature

Harmonic

Induction motor

Microcontroller

Running capacitor

\begin{abstract}
The main aim of this work is to analyze the input current waveform for a single-phase induction capacitor-run motor (SIMCR) to detect the faults. Internal and external faults were applied to the SIMCR and the current was measured. An armature (broken rotor bar) and bearing faults were applied to the SIMCR. A microcontroller was used to record the motor current signal and MATLAB software was used to analyze it with the different types of fault with varying load operations. Various values of the running capacitor were used to investigate the effect of these values on the wave-current shape. Total harmonic distortion (THD) for the voltage and current was measured. A deep demonstration of the experimental results was also provided for a better understanding of the mechanisms of bearing and armature faults (broken rotor bars) and the vibration was recorded. Spectral and power analyses revealed the difference in total harmonic distortion. The proposed method in this paper can be used in various industrial applications and this technique is quite cheap and helps most of the researchers and very effectual.
\end{abstract}

This is an open access article under the $\underline{C C B Y-S A}$ license.

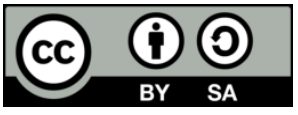

\section{Corresponding Author:}

Omar Sharaf Al-deen Alyozbaky

Department of Electrical Engineering

College of Engineering, University of Mosul

Ninava, Iraq

Email: o.yehya@uomosul.edu.iq

\section{INTRODUCTION}

A squirrel cage induction motor (IM) is a particularly good device. The motor design helps the machine to run in different rugged conditions. Different failures/abnormal conditions may occur, including bearing errors, rotor defects and stator defects. A system should therefore be established to identify the defects and isolate the motor from supply when necessary. Bearing faults are the most frequent issue in electric motors $(41 \%)$ based on a study of the reliability of IEEE motor, followed by rotor fault (10\%) and stator fault (37\%) [1]. Numerous methods have been employed to detect the different types of faults in an IM [2-5]. These [6-10] apply to the current spectrum, vibration analysis, and other techniques to detect the different faults in the motors. Another study reported the impacts of motor and simulated motors, which were examined using motor current signature analysis (MCSA) and also through observation of magnetic flux density outside the motor [11]. Different approaches have been adopted to control the [4, 12-15] these approaches are explained below. Several experimental outcomes were provided to showing the impact of bearing and armature faults in single-phase induction motor [16]. Cyclo-converter was employed for speed control by directly regulating the supply frequency [17]. Speed can also be controlled using the pulse with modulation (PWM) approach and this can be performed by using 8051 microcontrollers. Table 1 shown the Fault occurrence possibilities of various faults in the induction motor. 
Table 1. Fault occurrence possibilities of various faults in the induction motor [17]

\begin{tabular}{ccccc}
\hline Studied by & Bearing Fault (\%) & Stator Fault (\%) & Rotor Fault (\%) & Others (\%) \\
\hline IEEE & 42 & 28 & 8 & 22 \\
EPRI & 41 & 36 & 9 & 14 \\
\hline
\end{tabular}

In recent years' engineers and companies (Siemens, and Dreisilker) have introduced techniques to monitor machines $[18,19]$. Online machine monitoring also makes it possible for intelligent maintenance by optimizing the use of maintenance resources. Comprehensive experimental studies are very important to analyze the current signature for the induction motor to fully estimate the preventive maintenance diagnostics and failure prevention in drive systems which use induction motors. In [20], the results are depicting that four proposed PWM technique is less effective among PD PWM. Explanations of diagnostic techniques of machines are available in recent literature [21]. Details of diagnostic techniques of bearings are also presented in [22]. The diagnostic approaches have their basis in a number of signals including electric current, vibrations [23-25], acoustic signals [26-28].

In this paper, an easy method was presented to analyze the current signal of a single-phase induction motor to detect the faults. The rest of this paper is organized as: Research significant in section 2, Method, tools and the descriptions of code, hardware and device measurements are presented in section 3 . The research findings on motor fault identification are presented and discussed in section 4.

\section{RESEARCH SIGNIFICANCE}

Although modern instruments have been widely used on the faults diagnosis for induction motor in global laboratories, there has still some gaps that are not addressed in the previous works. Signal analysis is an important aspect of electrical engineering. This paper attempts to provide more detailed investigations regarding the effects of faults. The findings of this study will help the engineering designer to a deep understanding of the faults and their impact on the performance of the motor. Arduino internal memory was used to record the last case of the motor current when a serious fault was detected, then we can display and examine the frequency components of the motor current using MATLAB software after shutting down the machine. The current study contributes to our knowledge by addressing four important issues. First, the relationship between the input current with the different faults in the different operation loads. Second, the impact of the faults on the values of THD for the voltage and the current in the different operation loads. Third, the obvious effect on the power factor (pf) and vibration of the motor during operation in the various loads. Finally, the effect of the value of capacitor-run on the motor when working in different faults. The proposed method in this paper can be used in various industrial applications and this technique is quite cheap and helps most of the researchers and very effectual.

\section{RESEARCH METHOD AND MATERIALS}

Nearly $40-50 \%$ of all motor failures are related with the bearing issue. Bearing faults might manifest themselves as rotor asymmetry faults, otherwise, they can be classified the ball bearing related faults as inner and outer bearing defect, ball defect, and train defect. Harmonic components introduced by bearing failures in the line current spectrum is given by (1) [29]:

$$
f_{b g}=f \pm k f_{i, o, p}
$$

For inner race defect:

$$
f_{i}=Z f_{r} / 2\left(1+\frac{d}{D} \cos \alpha\right)
$$

For outer race defect:

$$
f_{o}=Z f_{r} / 2\left(1+\frac{d}{D} \cos \alpha\right)
$$

For ball defect:

$$
f_{b}=Z f_{r} / d\left(1-\frac{d^{2}}{D^{2}} \cos ^{2} \alpha\right)
$$


where: $\mathrm{Z}$ is the number of balls in the bearing, $\mathrm{D}$ is the diameter of the pitch circle, $\alpha$ is the contact angle in radians, $\mathrm{fb}$ is a mechanical frequency depending on the type of fault and on the bearing characteristics, fr is the rotor frequency. The double-revolving filed theory can be effectively used to obtain the equivalent circuit of a single-phase induction motor [30]. The method consists of determining the values of both the fields clockwise and anticlockwise at any given slip (s). As the core loss is neglected, Ro is not existing in the equivalent circuit. Furthermore, the $\mathrm{X} 0$ is half of the actual magnetizing reactance of the motor. The voltage on the main winding (m) and auxiliary winding (a) is the same voltage form the power supply. The sequence components for the voltage supply, it has forward (Vf) and backward ( $\mathrm{Vb}$ ) components. The impedances value of the stator $\left(\mathrm{Z}_{1}\right)$ is:

$$
Z_{1}=\left(R_{1}+j x_{1}\right)
$$

The impedances value of the forward field ( $\mathrm{Zf})$ and backward field $(\mathrm{Zb})$ in the any slip is:

$$
\begin{aligned}
& Z_{f}=\left(\frac{r_{2}{ }^{\prime}}{s}+j x_{2}{ }^{\prime}\right) / / j x o \\
& Z_{b}=\left(\left(\frac{r_{2}{ }^{\prime}}{(2-s)}\right)+j x_{2}{ }^{\prime}\right) / / j x o
\end{aligned}
$$

where: $r_{2}{ }_{2}$ rotor resistance refers to stator winding, $x_{2}^{\prime}$ rotor reactance refers to stator winding and $x m$ magnetic reactance. Under standstill condition, $s=1$ and $2-s=1$ hence $\mathrm{Zf}=\mathrm{Zb}$ and hence $\mathrm{Vf}=\mathrm{Vb}$, but in the running condition, Vf becomes almost 90 to $95 \%$ of the applied voltage. So, the equivalent impedance is:

$$
Z_{e q}=Z_{1}+Z_{f}+Z_{b}
$$

The equivalent circuit referred to the stator is shown in Figure 1.

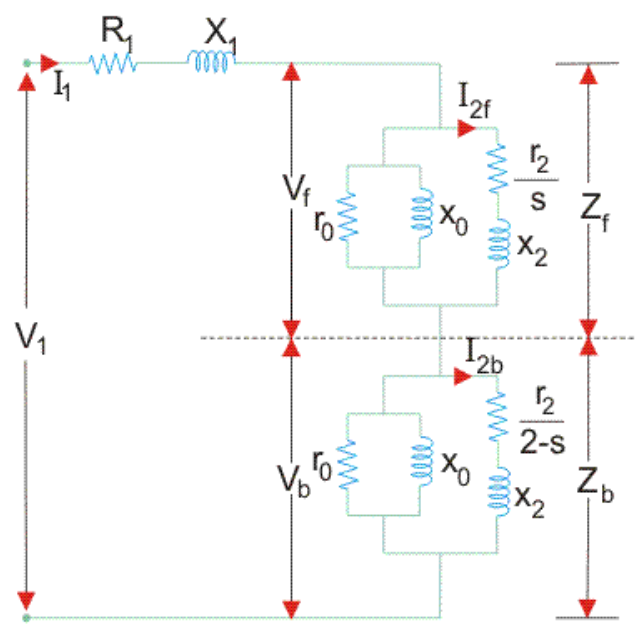

Figure 1. Equivalent circuit of Single-phase induction motor without core loss

The currents through forward and backward rotor referred to stator are:

$$
\begin{aligned}
& I_{2 f}=\frac{V_{f}}{\left(\frac{r_{2}}{s}+j x_{2}\right)} \\
& I_{2 b}=\frac{V_{b}}{\left(\frac{r_{2}}{2-s}+j x_{2}\right)}
\end{aligned}
$$


where $V_{f}=I_{1} \times Z_{f}$ and $V b=I_{1} \times Z_{b}$, the power input $\left(P_{f}\right)$ to forward filed rotor and the power input $\left(P_{b}\right)$ to the backward are:

$$
\begin{aligned}
& P_{f}=\left(I_{2 f}\right)^{2}\left(\frac{r_{2}}{s}\right) \text { watt }- \\
& P_{b}=\left(I_{2 b}\right)^{2}\left(\frac{r_{2}}{2-s}\right) \text { watt }- \\
& P_{m}=(1-s) \times\left(P_{f}-P_{b}\right) \\
& P_{\text {out }}=P_{m}-(\text { mechanical }+ \text { core }) \text { Losses } .
\end{aligned}
$$

Furthermore, the forward torque $\left(\mathrm{T}_{\mathrm{f}}\right)$ and backward torque $\left(\mathrm{T}_{\mathrm{b}}\right)$ for the single phase induction motor are:

$$
\begin{gathered}
T_{f}=\frac{P_{f}}{\left(\frac{2 \times \pi \times N}{60}\right)} N-m . \\
T_{b}=\frac{P_{b}}{\left(\frac{2 \times \pi \times N}{60}\right)} N-m .
\end{gathered}
$$

While the shaft torque is:

$$
T_{\text {sh }}=\frac{P_{\text {out }}}{\left(\frac{2 \times \pi \times N}{60}\right)} N-m
$$

where $\mathrm{N}$ in the motor speed, the input power:

$$
P_{i n}=V \times I_{t} \times \cos \theta_{t}
$$

We denote by $\theta \mathrm{m}$ the phase angle of the current in main winding, by $\theta \mathrm{a}$ the phase angle of the current in auxiliary winding, by $\theta \mathrm{r}$ the phase angle of the input current and by $\theta \mathrm{t}$ the phase angle between the input current with the voltage. The efficiency for the single phase induction motor is:

$$
\operatorname{Efficiency}(\eta)=\frac{P_{o u t}}{P_{i n}}
$$

Induction motor faults can be detected accurately under both stationary and non-stationary states. Armature and bearing faults were inducted into the induction motor. Both normal and faulty signatures were acquired under different speed and load conditions. To address the detection abilities of the above methods, comparisons are completed in both the time and frequency domains. In the frequency domain, spectral differences are characterized by constant speed conditions and compared. A practical test was conducted on SIMCR. The tests were carried out in the laboratories of the Department of Electrical Engineering, University of Mosul, Iraq. The main apparatus consisted of a SIMCR with a rated power of 0.5 HP, $220 \mathrm{~V}$ and $50 \mathrm{~Hz}$ as displayed in Figure 2. The loading mechanism was optioned by using mechanical load.

For armature faults, we had made 4 holes in the armature of $6 \mathrm{~mm}$ diameter and $4 \mathrm{~mm}$ deep in opposite directions as display in Figure 3. For bearing faults, we had considered a real induction machine with bearing problems like improper lubrication, overloading, fatigue, and uneven wear. Different values of running capacitors have been used to identify the impact of changing running capacitor to the performance of the SIMCR. To validate this work, actual data from the motor manufacturer were used to compare the results. Furthermore, Table 2 shows the characteristics of this motor. Arduino Due which has been used in this work, is the first Arduino board using 32-bit ARM core microcontroller. 


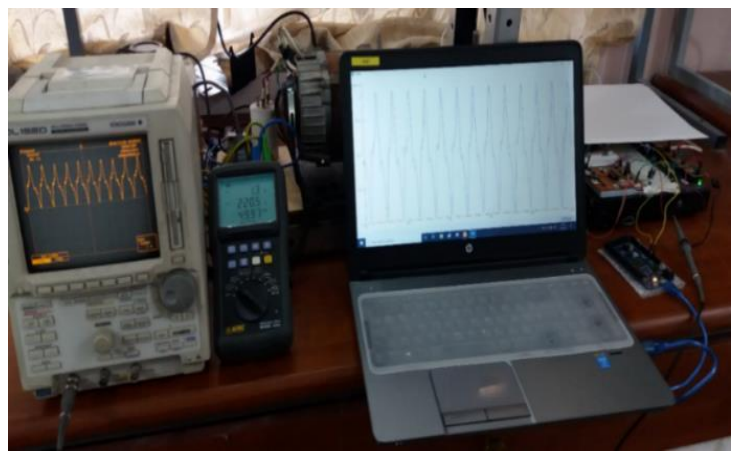

Figure 2. View of the experimental setup

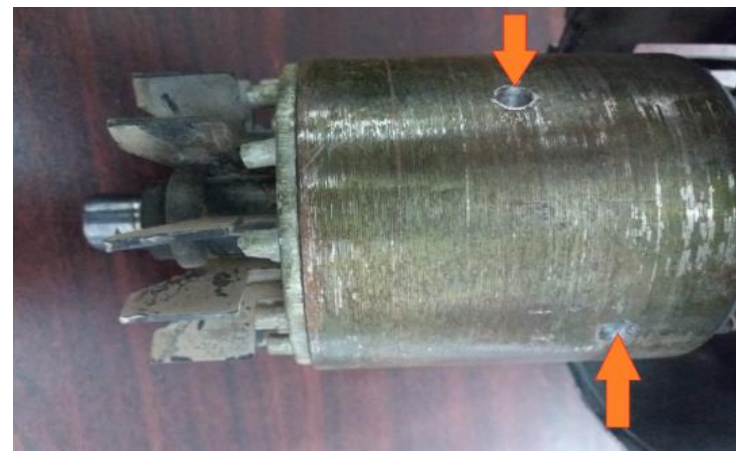

Figure 3. The motor's armature holes to simulate the armature fault

Table 2. Characteristics of single phase induction motor

\begin{tabular}{cc}
\hline Parameter & Specifications \\
\hline Input voltage & $220(\mathrm{~V})$ \\
Frequency & $50(\mathrm{~Hz})$ \\
Power & $370(\mathrm{Watt})$ \\
Rated Current & $3(\mathrm{~A})$ \\
Reference speed & $1425(\mathrm{R} . \mathrm{P} . \mathrm{M})$ \\
Ambien Temperature & $35^{\circ} \mathrm{C}$ \\
Capacitor-run & $16 \mu \mathrm{F}$ \\
\hline
\end{tabular}

It has 12 analog inputs, 4 UARTs (hardware serial ports) and clock speed of $84 \mathrm{MHz}$ as presented in Table 3. This unit was used for data acquisition. The sensor current signal acquisition process was done using Arduino board after the signal conditioning circuit as shown in Figure 4 (first stage). Arduino Due board converts the analog signal into digital form then sends it over USB cable to PC or laptop for displaying purposes or for further analysis using MATLAB software.

\begin{tabular}{|c|c|}
\hline Microcontroller & AT91SAM3X8E \\
\hline Operating Voltage & $3.3 \mathrm{~V}$ \\
\hline Analog Input & 12 Pins \\
\hline Clock Speed & $84 \mathrm{MHz}$ \\
\hline Digital I/O & 54 pins \\
\hline UART & 4 hardware serial ports \\
\hline PWM & 12 pins \\
\hline SRAM & $96[\mathrm{~KB}]$ \\
\hline Flash & $512[\mathrm{~KB}]$ \\
\hline
\end{tabular}

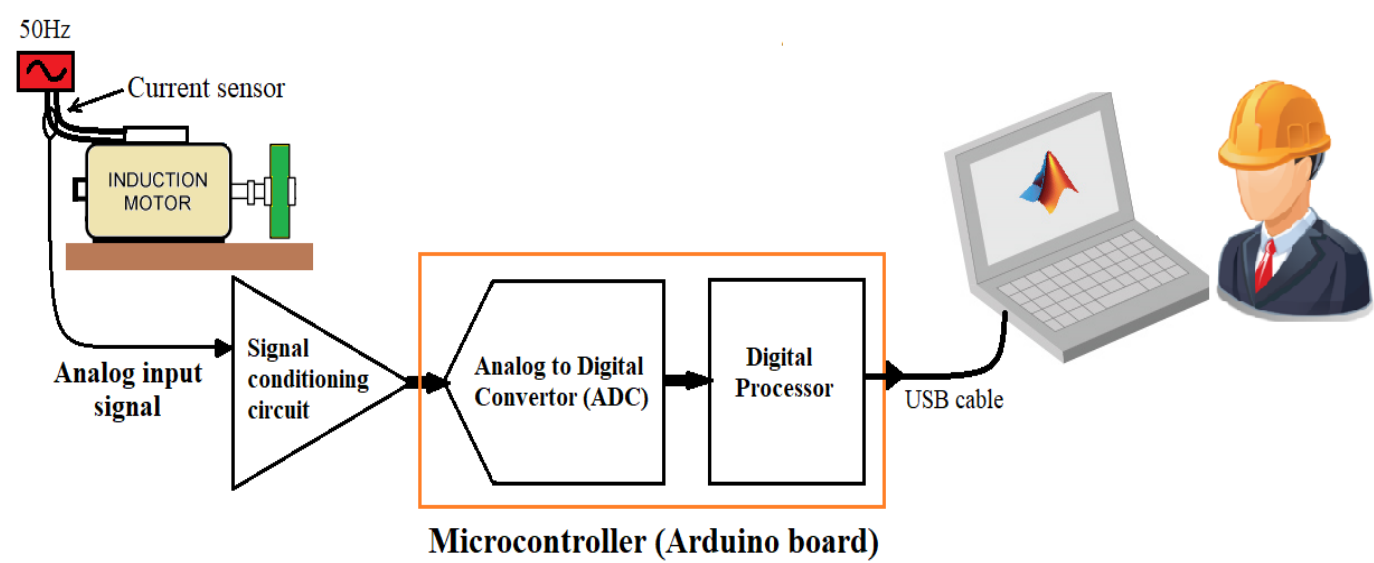

Figure 4. Schematic diagram of the experimental setup 
The sampling frequency was determined by applying a test signal (sin wave) of a $5 \mathrm{KHz}$ (or any value) from an accurate function generator to Arduino analogue input. The Arduino ADC will convert it to digital values then after log the readings to MATLAB using Tera-term software, the sampling frequency (1/Ts) can obtain using:

$$
T s=\frac{\text { Signal Period } T}{N}
$$

where, $\mathrm{N}$ is the number of samples in one period and signal period (T) measured in second. The sampling time for Arduino due which is computed using the above equation is approximately 6.25 usec, in this work we put a delay of $500 \mathrm{usec}$ between each analogue read so that the sampling frequency is approximately $1975 \mathrm{~Hz}$.

In this paper a method is proposed to record last motor case when a fault occurred and before motor shutdown using Arduino due microcontroller as shown in Figure 5. In the normal case, motor current reading is from the sensor monitored continuously on PC screen. When a fault occurs, the procedure in this case must be carried out as quickly as possible to start recording the motor current reading and save it in Arduino flash memory and then sending a digital command to shut down the motor, after which the data must be transferred to the PC (or laptop) for analysis.

As shown in the flow chart, firstly, we set the value of data points of motor current to 1002 points, we take 1002 readings from the current sensor (with a sampling time of $506.25 \mathrm{usec}$ ), so 1002 readings are enough to sample 26 cycles). In normal cases for the motor current, the readings continuously sent to PC serial monitor and the current sensor used in this work was RS-Carlo Gavazzi, 0.5-5 A input shown in Figure 5. We make a threshold voltage of $3.3 \mathrm{~V}$ to take a decision for maximum voltage coming from the signal conditioning circuit to the analog input pin as shown in Figure 5.

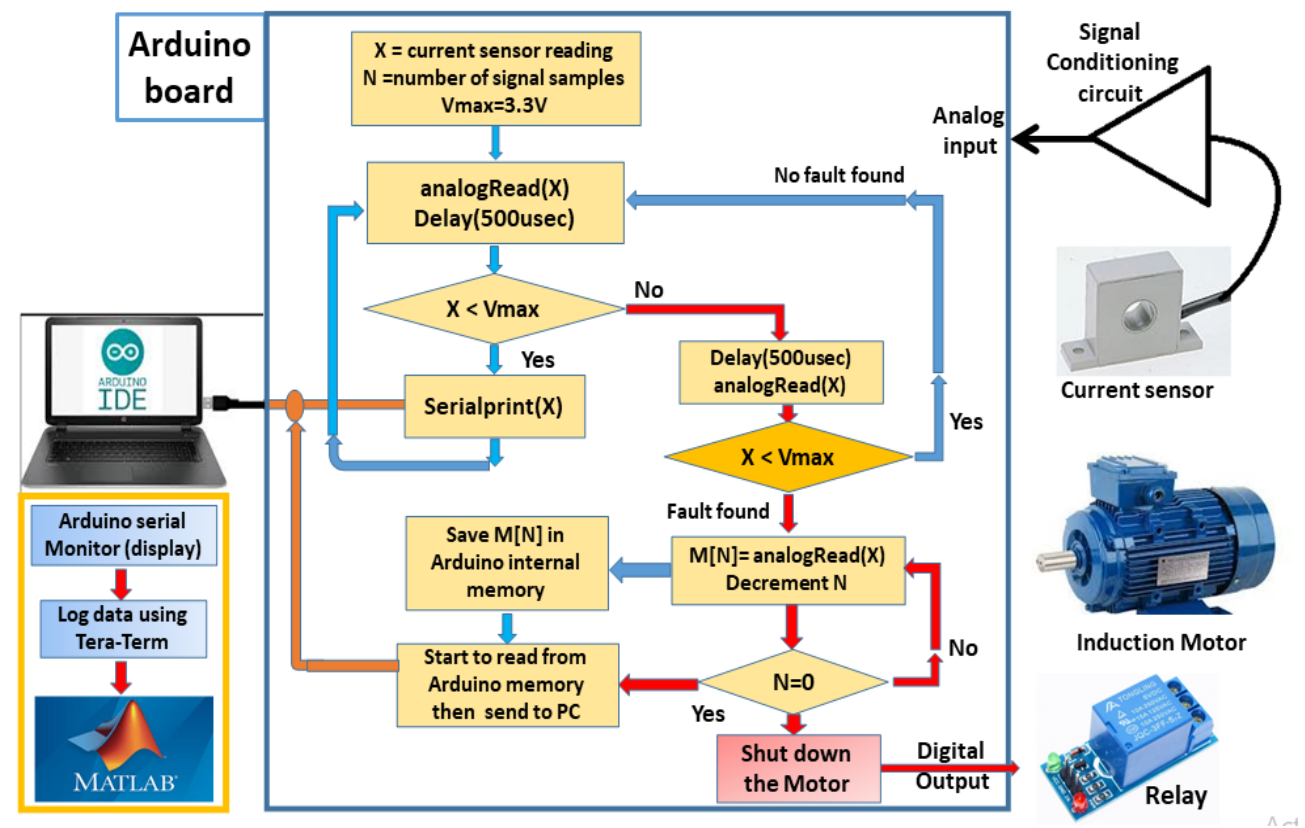

Figure 5. Framework of the proposed method

The microcontroller reads the motor current from the sensor, checks it with a specific value and makes a comparison. If the current reading value is normal the Arduino board sends the sensor current reading to the PC over a USB cable for displaying purposes. When an abnormal reading was detected, another test is done after $0.5 \mathrm{sec}$ from the first abnormal reading, if it is still there being a reading greater than $3.3 \mathrm{~V}$ (fault detection), the program path now starts to record motor current at that moment (needs 0.5 seconds for recording), turn the motor off, and send the readings to a PC (laptop) via a USB cable in order to analyze the data (motor current) using MATLAB. The signal recording time for 1002 readings can be calculated, so, the recording time for 1002 readings $(N)=(6.25 \mathrm{usec}+500 \mathrm{usec}$ (delay between each analogue read)) $* 1002=0.5 \mathrm{sec}$. 


\section{RESULTS AND DISCUSSION}

In this work the proposed data acquisition method can be used to analyze machine fault by recording sensor data as soon as a fault was detected, then shut down the system after that signal analysis can be down using MATLAB. Using the low cost Arduino platform with MATLAB as data acquisition can be used widely in university laboratories for educational purpose. It is interesting to compare the data of Table 4 with the different load operations. It appears that there are differences between the values of power and total harmonic distortion of the voltage and currents in the different loads with different running capacitors. Furthermore, the vibration as mean and maximum values was present when the motor worked in a different load operation with different running capacitors.

Table 4. Different load operations with different running capacitor values (experimental results)

\begin{tabular}{|c|c|c|c|c|c|c|c|c|}
\hline \multicolumn{2}{|c|}{$\mathrm{C}=10$ microfarad } & I & $\mathrm{Pm}$ & $\mathrm{PF}$ & THD (V) & THD (I) & Vib max & Vib mean \\
\hline \multirow[t]{3}{*}{ Normal } & No-load & 1.9 & 199 & 0.47 & 2.2 & 9.4 & 4.1 & 3 \\
\hline & $70 \%$ & 2.1 & 339 & 0.68 & 1.7 & 6.5 & 3.9 & 3.1 \\
\hline & $100 \%$ & 2.9 & 518 & 0.8 & 1.7 & 5.5 & 5.3 & 4.6 \\
\hline \multirow[t]{3}{*}{ Ab-normal } & No-load & 1.8 & 134 & 0.3 & 2.4 & 14 & 5.71 & 4.7 \\
\hline & $70 \%$ & 2.2 & 318 & 0.66 & 2.4 & 7.2 & 5.3 & 4.5 \\
\hline & $100 \%$ & 3 & 500 & 0.78 & 2.5 & 6.6 & 5.5 & 4.6 \\
\hline \multicolumn{2}{|c|}{$\mathrm{C}=16$ microfarad } & I & $\mathrm{Pm}$ & $\mathrm{PF}$ & THD (V) & THD (I) & Vib max & Vib mean \\
\hline \multirow[t]{3}{*}{ Normal } & No-load & 1.5 & 241 & 0.73 & 1.5 & 7.1 & 4.4 & 3 \\
\hline & $70 \%$ & 2.1 & 415 & 0.89 & 1.7 & 13.1 & 5.5 & 4.5 \\
\hline & $100 \%$ & 3 & 621 & 0.93 & 1.6 & 8.7 & 6.1 & 5.1 \\
\hline \multirow[t]{3}{*}{ Ab-normal } & No-load & 1.4 & 194 & 0.64 & 2.3 & 32 & 4.6 & 4 \\
\hline & $70 \%$ & 2.1 & 425 & 0.8 & 2.4 & 18 & 5.6 & 4.5 \\
\hline & $100 \%$ & 3.1 & 601 & 0.87 & 2.3 & 14 & 6.4 & 5.4 \\
\hline \multicolumn{2}{|c|}{$\mathrm{C}=20$ microfarad } & I & $\mathrm{Pm}$ & $\mathrm{PF}$ & THD (V) & THD (I) & Vib max & Vib mean \\
\hline \multirow[t]{3}{*}{ Normal } & No-load & 1.5 & 300 & 0.91 & 1.6 & 24 & 4.6 & 3.2 \\
\hline & $70 \%$ & 2.1 & 437 & 0.97 & 1.5 & 15.9 & 4 & 4.3 \\
\hline & $100 \%$ & 2.9 & 630 & 0.97 & 1.5 & 9.5 & 5.7 & 5.3 \\
\hline \multirow[t]{3}{*}{ Ab-normal } & No-load & 1.2 & 210 & 0.79 & 2.4 & 36 & 5.2 & 4.3 \\
\hline & $70 \%$ & 2.1 & 433 & 0.95 & 2.5 & 19.3 & 5.5 & 4.5 \\
\hline & $100 \%$ & 3.1 & 620 & 0.91 & 2.4 & 14.8 & 5.9 & 5.1 \\
\hline \multicolumn{2}{|c|}{$\mathrm{C}=25$ microfarad } & I & $\mathrm{Pm}$ & $\mathrm{PF}$ & THD (V) & THD (I) & Vib max & Vib mean \\
\hline \multirow[t]{3}{*}{ Normal } & No-load & 1.7 & 364 & 0.97 & 1.5 & 22 & 4.3 & 3.5 \\
\hline & $70 \%$ & 2.1 & 445 & 0.98 & 1.5 & 17.7 & 4.7 & 3.8 \\
\hline & $100 \%$ & 2.9 & 644 & 0.98 & 1.5 & 10.6 & 6.2 & 5.3 \\
\hline \multirow[t]{3}{*}{ Ab-normal } & No-load & 1.3 & 262 & 0.87 & 1.7 & 38 & 4.9 & 4.1 \\
\hline & $70 \%$ & 2.1 & 425 & 0.97 & 2.4 & 19.1 & 5.3 & 4.5 \\
\hline & $100 \%$ & 3.1 & 636 & 0.93 & 2.4 & 14.3 & 6.7 & 5.4 \\
\hline
\end{tabular}

The discussion of the results begins with an explanation of the difference between bearing and armature faults in respect of normal cases. It clearly appears in Table 4 that the power factor of the motor (in normal case) is better than from the power factor of the motor (abnormal case) when it is working with 16 microfarads. The THD of the current of the motor (abnormal case) at the c run $=16$ microfarad is higher than from the motor (normal case), because of the distortion in the input current. the distortion was happened because of the bearing and armature faults as shown in the Table 4.

Furthermore, the results reveal that the vibration of the normal motor is less than that from the abnormal motor as displayed in the Figure 6. The frequency components clearly shown in Figure 7(a) and (b) by the red arrows, are due to bearing and armature faults compared with normal (blue) case in the no load test when $\mathrm{C}=16 \mathrm{uF}$ (standard value). To compare between normal and abnormal operation for SIMCR, the THD for the input current were measured as shown in Figure 7. The waveforms shown in Figure 8 (frequency domain) for each test case of motor current (normal, bearing and armature) are plotted in time domain as shown in Figure 9.

If any abnormality mechanical faults happened during the motor working. The harmonic is generated in the motor, accompanied by speed and slip oscillation, and distortion of the stator current. Furthermore, the characteristic of frequency components for the type of abnormality appears in the power spectrum of stator current. These components allow the location of identifying the abnormality. Figures 8-13 show the spectral comparisons of current signatures around the fundamental frequency under normal and abnormal fault conditions. The measurements were taken at $50 \mathrm{~Hz}(1425 \mathrm{RPM})$ and different load conditions. The impact of load on abnormal induced sidebands is illustrated in Figures 8-13. Figures 8-13 show the comparisons of both the left and right sideband amplitudes between a normal and abnormal at $50 \mathrm{~Hz}$ and under three load conditions (e.g. 0\%, 70\%, and 100\%). 


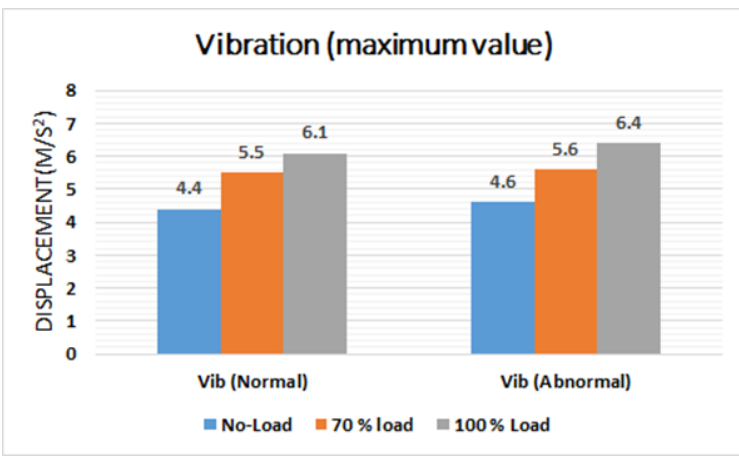

Figure 6. Vibration (maximum values) at c run=16 microfarad

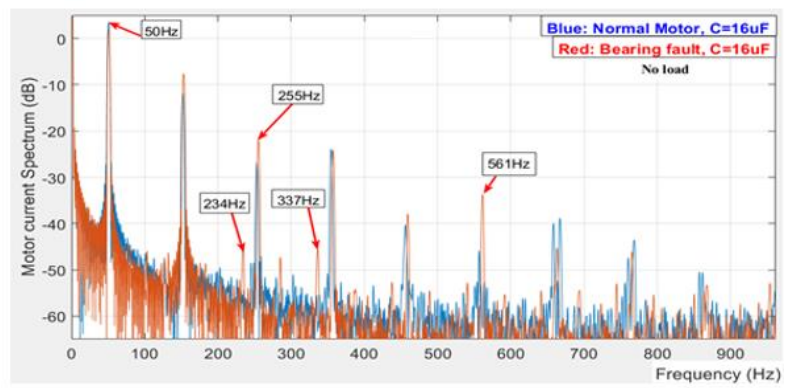

(a)

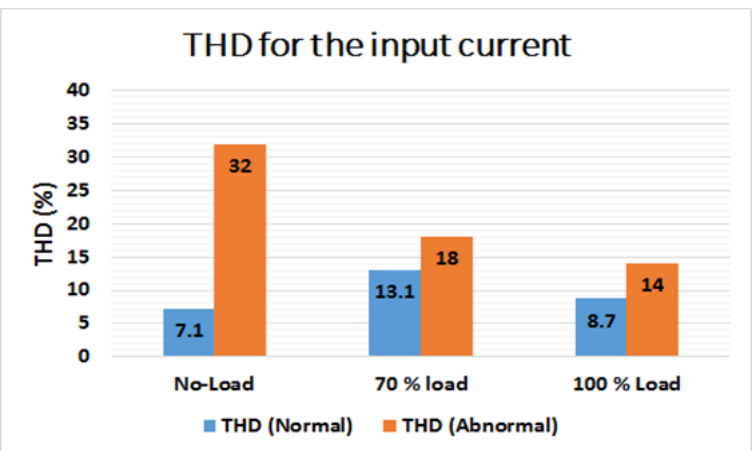

Figure 7. THD (for the input current) at c run=16 microfarad

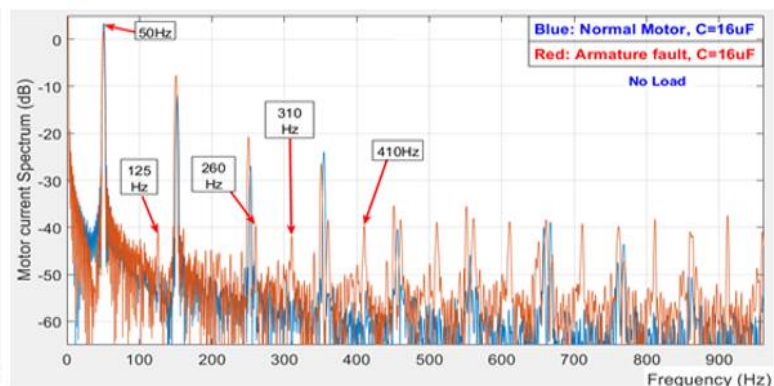

(b)

Figure 8. The difference between motor current spectrum (no load); (a) normal case and bearing fault, (b) normal case and armature fault

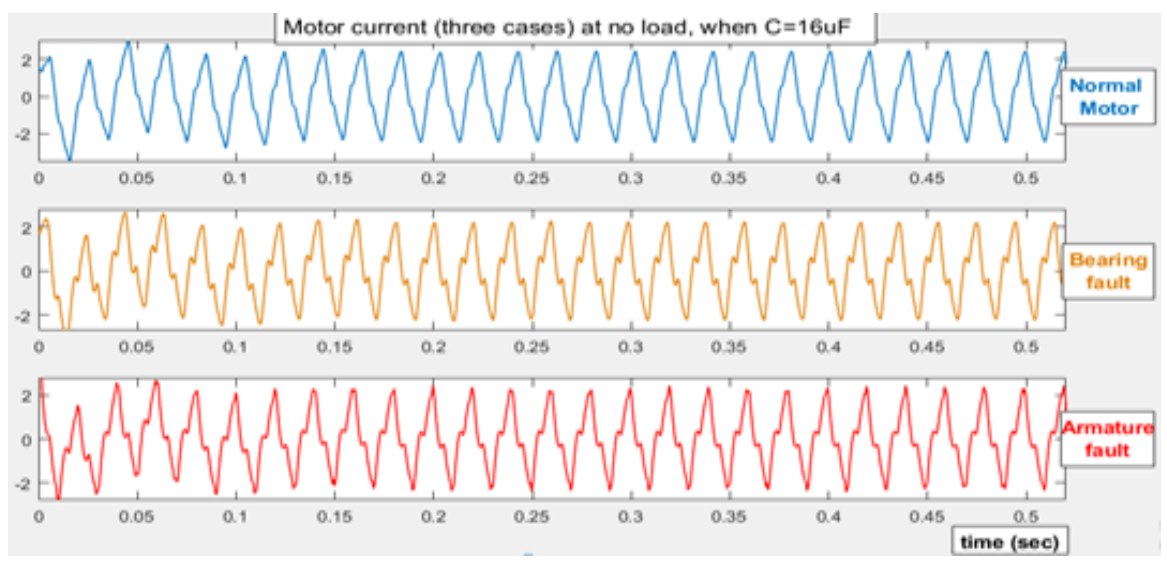

Figure 9. Motor current differences between bearing and armature faults with regard to normal case in the frequency window $(0-1000 \mathrm{~Hz}$, Figure 8$)$

Generally, the sidebands from motor current signatures are more sensitive to load variations. In full load test, Figure 10(a) shows the frequency components (red arrows) due to bearing faults while Figure 10(b) shows the frequency components due to armature faults (red arrows), when $\mathrm{C}=16 \mathrm{uF}$ (standard value). The time domain of the waveforms shown in Figure 11 for each test case (normal, bearing fault, and armature fault) are plotted.

To grasp the different steps involved in locating abnormal faults in the frequency spectrum using fault frequencies from different signals. A normal motor $(1.1 \mathrm{~kW})$ under various load testes was considered to identify the correct fault frequency peaks in the current spectrum as shown in Figure 10. Obviously, in the 
Figure 10, the fundamental $50-\mathrm{Hz}$ component appears in the spectrum of current, while eminent sideband components appear at $27 \mathrm{~Hz}$ and $73 \mathrm{~Hz}$, i.e., at $50 \mathrm{~Hz}$ (fundamental frequency).

When a capacitor of $10 \mathrm{uF}$ is used instead of standard $16 \mathrm{uF}$, the high frequency components above $180 \mathrm{~Hz}$ for normal case are shown clearly (blue arrows) in Figures 12(a) and (b) compared to bearing and armature faults in full load test, while at frequencies under $170 \mathrm{~Hz}$ the frequency component values in fault cases (bearing and armature) are greater than normal case (red arrows). Figure 13 shows the time domain for each test case of motor current (normal, bearing fault, and armature fault).

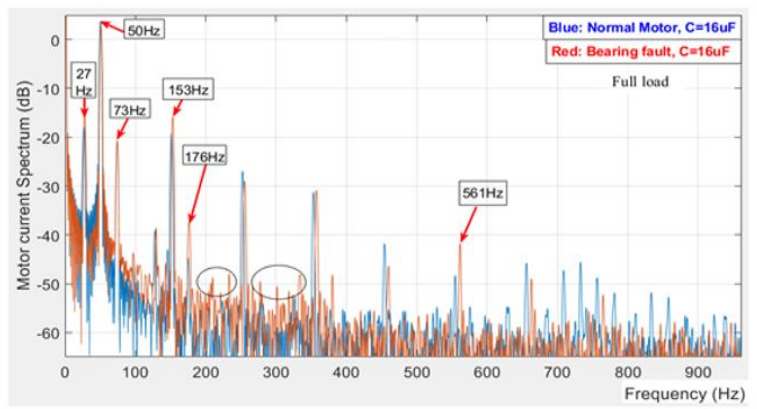

(a)

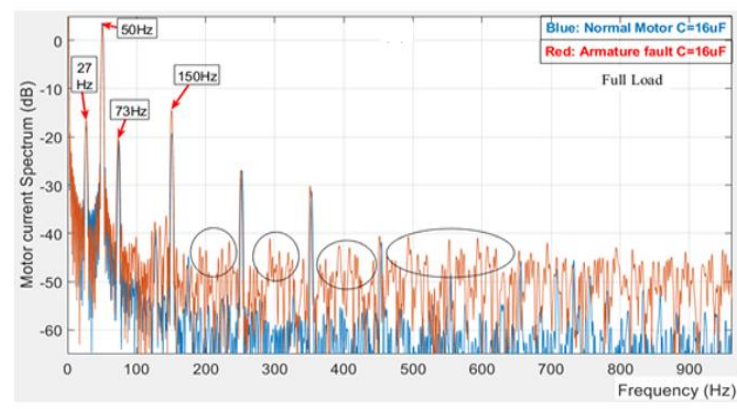

(b)

Figure 10. The difference between motor current spectrum (full load); (a) normal case and bearing fault, (b) normal case and armature fault

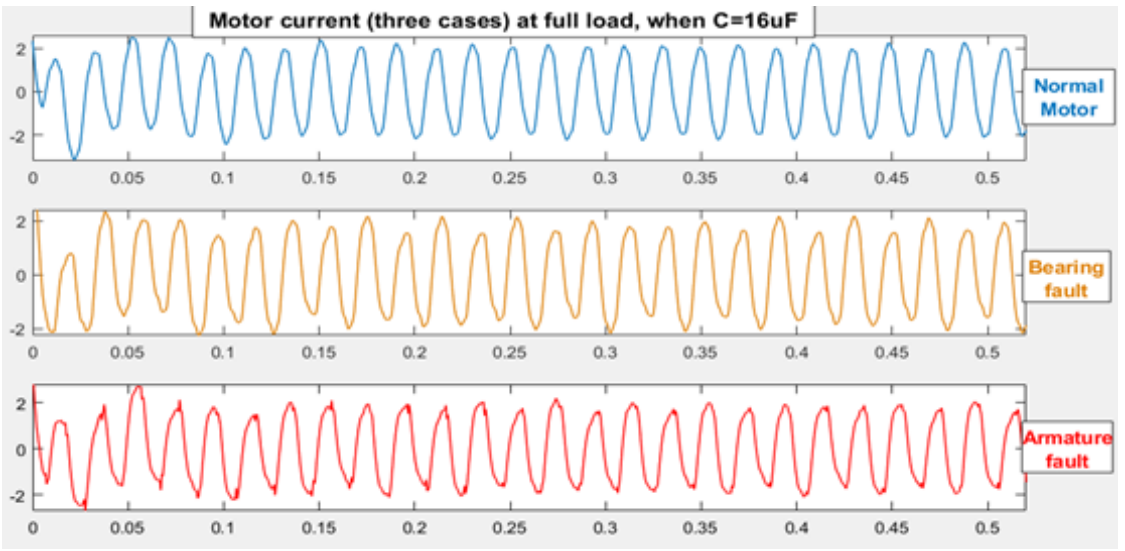

Figure 11. Motor current differences between bearing and armature faults with regard to normal case in the frequency window $(0-1000 \mathrm{~Hz}$, Figure 10)

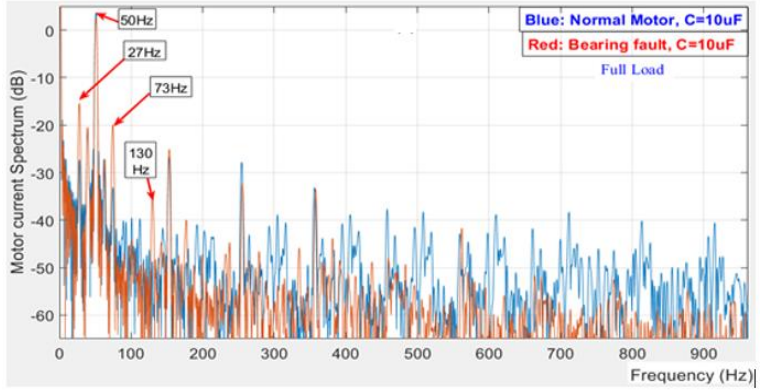

(a)

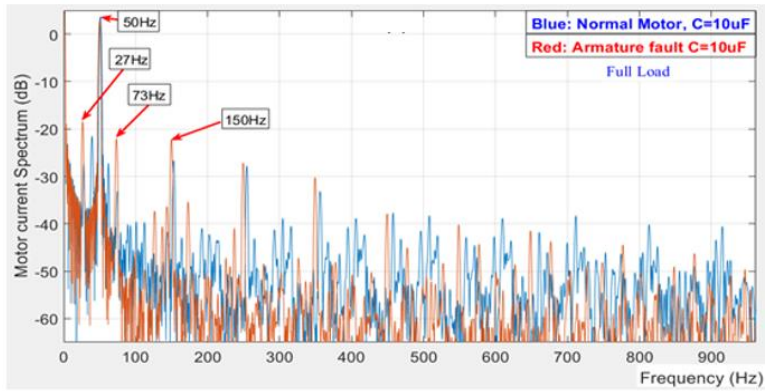

(b)

Figure 12. The difference between motor current spectrum (full load); (a) normal case and bearing fault, (b) normal case and armature fault 


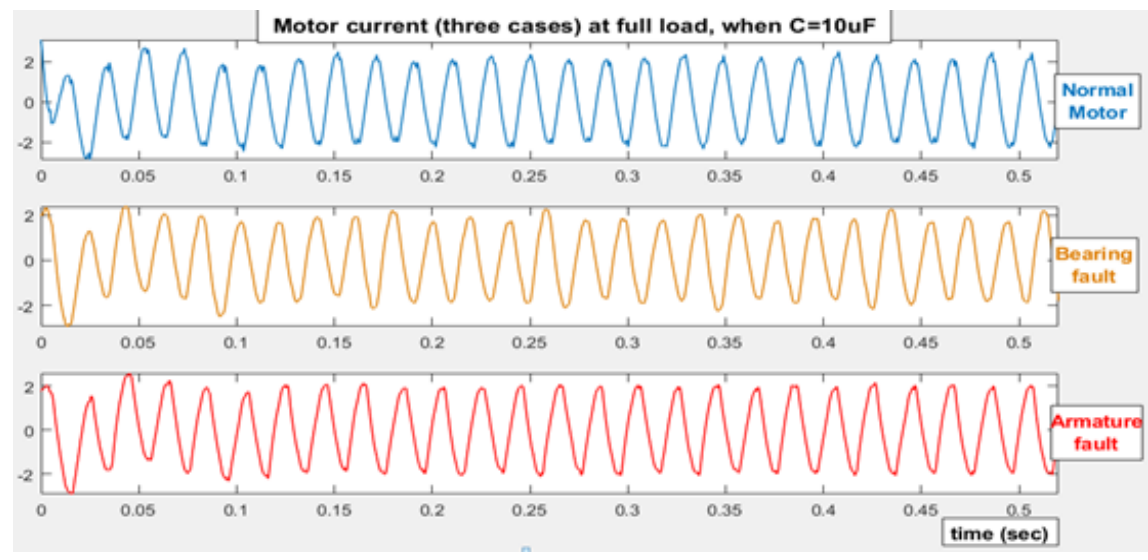

Figure 13. Motor current differences between bearing and armature faults with regard to normal case in the frequency window $(0-1000 \mathrm{~Hz}$, Figure 12)

\section{CONCLUSION}

The present study revealed the effect of bearing and armature faults on the performance and characteristics of SIMCR. In comparison, the aim of this work is to examine variations in the amplitudes of the fault frequency components between the normal motor and faulty motor in a wide range of loading conditions. A clear difference in the value of power absorbed from the source was observed between the different cases. The results showed distortions in the current wave were because of these faults (bearing and armature) when the motor operated in different loads with different running capacitors. One of the more significant findings to emerge from this study is to propose easy and cheap tools to analyze the spectrum of any electrical machine. Arduino internal memory was used to record the last case of the motor current when a serious fault was detected, then we can display and examine the frequency components of the motor current using MATLAB software after shutting down the machine. The results were validated against the manufacturer's experimental data. The results from the current spectra analysis in which the abnormally fault frequency components are suitable to detect anomaly faults at any level of loading conditions. The method adopted in this work is quite cheap and helps most of the researchers and very effectual to detecting the different faults of the induction motor. More information on fault diagnosis by using the current signature would help to establish a greater degree of accuracy on this matter.

\section{ACKNOWLEDGEMENTS}

The authors would like to thank Mosul University, College of Engineering, Electrical Department, for the support given during this work

\section{REFERENCES}

[1] S. F. Legowski, S. Member, A. H. M. S. Ula, and A. M. Trzynadlowsh, "Instantaneous Signature Analysis of hductio," IEEE Transactions on Industry Applications, vol. 32, no. 4, pp. 904-909, 1996.

[2] P. P. S. Saputra, Misbah, H. Ariwinarno, and F. D. Murdianto, "Various and multilevel of wavelet transform for classification misalignment on induction motor with quadratic discriminant analysis," TELKOMNIKA (Telecommunication Computing Electronics and Control), vol. 18, no. 2, pp. 961-969, 2020.

[3] L. Salah, G. Adel, K. Khaled, B. Ahmed, and A. Issam, "Broken rotor bar fault diagnostic for DTC Fed induction motor using stator instantaneous complex apparent power envelope signature analysis," International Journal of Power Electronics and Drive Systems (IJPEDS), vol. 10, no. 3, pp. 1187-1196, 2019.

[4] A. S. Hussein and M. N. Hawas, "Power quality analysis based on simulation and MATLAB/Simulink," Indonesian Journal of Electrical Engineering and Computer Science (IJEECS), vol. 16, no. 3, pp. 1144-1153, 2019.

[5] H. Ibrahim Shousha and A. B. Kotb, "Deriving the system equations of unbalanced two-phase induction motor," IAES International Journal of Robotics and Automation (IJRA), vol. 9, no. 3, pp. 171-177, 2020.

[6] Y. Zahraoui, M. Akherraz, C. Fahassa, and S. Elbadaoui, "Induction motor harmonic reduction using space vector modulation algorithm," Bulletin of Electrical Engineering and Informatics (BEEI), vol. 9, no. 2, pp. 452-465, 2020.

[7] K. A. M. Annuar, M. R. M. Sapiee, R. M. Nor, M. S. M. Azali, M. B. N. Shah, and S. M. Rozali, "Squirrel cage induction motor scalar control constant V/F analysis," TELKOMNIKA (Telecommunication Computing Electronics and Control), vol. 17, no. 1, pp. 417-424, 2019.

[8] A. Agrawal, R. S. Lodhi, and P. Nema, "Indirect vector control for induction motor drive using two level and five level inverter," International Journal of Applied Power Engineering (IJAPE), vol. 8, no. 2, pp. 134-144, 2019. 
[9] A. T. Abdullah and A. M. Ali, "Thermal analysis of a three-phase induction motor based on motor-CAD, flux2D, and matlab," Indonesian Journal of Electrical Engineering and Computer Science (IJEECS), vol. 15, no. 1, pp. 48-55, 2019.

[10] H. Echeikh, R. Trabelsi, H. Kesraoui, A. Iqbal, and M. F. Mimouni, "Torque ripples improvement of direct torque controlled five-phase induction motor drive using backstepping control," International Journal of Power Electronics and Drive Systems (IJPEDS), vol. 11, no. 1, pp. 64-74, 2020.

[11] C. M. Riley, K. Lin Brian, and T. G. Habetler, "A method for sensorless on-line vibration monitoring of induction machines," IEEE Transactions on Industry Applications, vol. 34, no. 6, pp. 1240-1245, 1998.

[12] H. A. Mohamed and H. M. D. Habbi, "Power quality of dual two-level inverter fed open end winding induction motor," Indonesian Journal of Electrical Engineering and Computer Science (IJEECS), vol. 18, no. 2, pp. 688-697, 2020.

[13] N. Murali and V. Balaji, "Real time FPGA Implementation of PWM Chopper Fed Capacitor Run Induction Motor," International Journal of Reconfigurable and Embedded Systems (IJRES), vol. 7, no. 3, pp. 138-148, 2018.

[14] S. Gobimohan and N. Murali, "Implementation of PWM AC chopper controller for capacitor run induction motor drive via bacterial foraging optimization algorithm," International Journal of Reconfigurable and Embedded Systems (IJRES) vol. 9, no. 3, pp. 169-177, 2020.

[15] G. Joshi and A. J. Pinto Pius, "ANFIS controller for vector control of three phase induction motor," Indonesian Journal of Electrical Engineering and Computer Science (IJEECS), vol. 19, no. 3, pp. 1177-1185, 2020.

[16] O. S. Alyozbaky and M. A. Al-Yoonus, "Faults diagnosis of a single-phase induction motor using microcontroller," International Journal of Advanced Science and Technology (IJAST), vol. 29, no. 3, pp. 4866-4875, 2020.

[17] R. Waswani, A. Pawar, M. Deore, and R. Patel, "Induction motor fault detection, protection and speed control using arduino," 2017 International Conference on Innovations in Information, Embedded and Communication Systems (ICIIECS), Coimbatore, 2017, pp. 1-5.

[18] M. Irfan, N. Saad, R. Ibrahim, and V. S. Asirvadam, "An on-line condition monitoring system for induction motors via instantaneous power analysis," Journal of Mechanical Science and Technology, vol. 29, no. 4, pp. 1483-1492, 2015.

[19] R. Islam, S. A. Khan, and J. M. Kim, "Discriminant Feature Distribution Analysis-Based Hybrid Feature Selection for Online Bearing Fault Diagnosis in Induction Motors," Journal of Sensors, vol. 2016, 2016.

[20] R. K. Bhukya and P. S. Kumar, "Simplified down sampling factor based modified SVPWM technique for cascaded inverter fed induction motor drive," International Journal of Advances in Applied Sciences (IJAAS), vol. 9, no. 1, pp. 20-26, 2020.

[21] D. Lopez-Perez and J. Antonino-Daviu, "Application of Infrared Thermography to Failure Detection in Industrial Induction Motors: Case Stories,” IEEE Transactions on Industry Applications, vol. 53, no. 3, pp. 1901-1908, 2017.

[22] B. Van Hecke, J. Yoon, and D. He, "Low speed bearing fault diagnosis using acoustic emission sensors," Applied Acoustics, vol. 105, pp. 35-44, 2016.

[23] D. H. Hwang, Y. W. Youn, J. H. Sun, K. H. Choi, J. H. Lee, and Y. H. Kim, "Support vector machine based bearing fault diagnosis for induction motors using vibration signals," Journal of Electrical Engineering and Technology, vol. 10, no. 4, pp. 1558-1565, 2015.

[24] S. Zhang, S. Lu, Q. He, and F. Kong, "Time-varying singular value decomposition for periodic transient identification in bearing fault diagnosis," Journal of Sound and Vibration, vol. 379, pp. 213-231, 2016.

[25] X. Yan, M. Jia, and L. Xiang, "Compound fault diagnosis of rotating machinery based on OVMD and a 1.5dimension envelope spectrum," Measurement Science and Technology, vol. 27, no. 7, 2016, Art. no. 075002.

[26] Z. X. Yang and J. H. Zhong, "A hybrid EEMD-based SampEn and SVD for acoustic signal processing and fault diagnosis," Entropy, vol. 18, no. 4, 2016, Art. no. 112.

[27] A. Glowacz and Z. Glowacz, "Diagnosis of stator faults of the single-phase induction motor using acoustic signals," Applied Acoustics, vol. 117, no. 11, pp. 20-27, 2017.

[28] J. Józwik, "Identification and Monitoring of Noise Sources of Cnc Machine Tools By Acoustic Holography Methods," Advances in Science and Technology-Research Journal, vol. 10, no. 30, pp. 127-137, 2016.

[29] Z. Ye and B. Wu, "A review on induction motor online fault diagnosis," Proceedings IPEMC 2000. Third International Power Electronics and Motion Control Conference (IEEE Cat. No.00EX435), Beijing, China, vol. 3, 2000, pp. 1353-1358.

[30] O. S. Alyozbaky, "Performance Analysis of a Single Phase Induction Motor For Different Values of Running Capacitor Abstract," Tikrit Journal of Engineering Sciences, vol. 18, no. 1, pp. 19-27, 2011.

\section{BIOGRAPHIES OF AUTHORS}

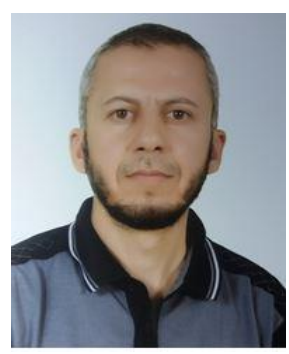

Marwan Abdulkhaleq Al-Yoonus was born in Mosul, Iraq on $18^{\text {th }}$ Act 1972. He obtained his Bachelor of Science (BSc) in Electrical Engineering in 1994 from Electrical Engineering Department, College of Engineering, University of Mosul, Iraq. Then he was appointed as an assistant engineer in the same mentioned department. After that, he got MSc in the subject (Design and simulation of driver for information transmission over optical communication system) in 2009 from the same mentioned department as well. Upon his graduation, he was appointed as teaching a staff (assistant lecturer) in the Electrical Engineering Department, College of Engineering, University of Mosul. 


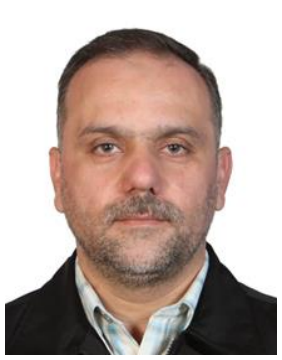

Omar Sh. Al-Yozbaky, he graduated with a B.Eng degree in Electrical Engineering from the College of Engineering, University of Mosul, Iraq, and in 2008 he obtained MSc degrees in electrical power engineering from the University of Mosul. While in 2017 obtained his Ph.D. from the University Putra Malaysia in Power Engineering. Currently, he is an Assistant Professor in the Department of Electrical Engineering, College of Engineering, University of Mosul. To date, he has authored and co-authored many scientific papers published in journals and conferences. His research interests include electrical machines, high voltage engineering, renewable energy, smart grid, and power system analysis. He is also a member of staff in the Department of Electrical Engineering, University of Mosul, Iraq. 